\title{
Effectiveness of violence prevention program on aggressive behaviors among preschool children
}

\author{
Eman S. Ahmmed * Marzoka A. Gadallah \\ Faculty of Nursing, Assiut University, Assiut, Egypt
}

Received: August 3, 2016

DOI: $10.5430 /$ jnep.v7n4p116
Accepted: November 8, $2016 \quad$ Online Published: December 11, 2016

URL: http://dx.doi.org/10.5430/jnep.v7n4p116

\begin{abstract}
Early childhood aggression is one of the strongest predictors of violence later in life, the earlier the application of intervention of violence prevention, the more reducing its occurrence later in life. The aim of this study was to assess the effectiveness of violence prevention program on aggressive behaviors among preschool children. A quazi experimental design was used in this study. This study was conducted in Bader Kindergarten at Assiut city. Two classrooms from KG2 were chosen one for the interventional group and the other is control. The Revised Aggression Scale (RAS-K-2) was used to assess aggression in

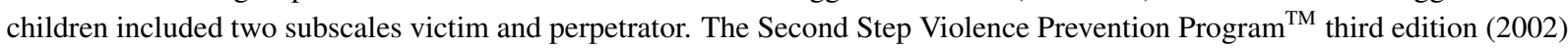
for Preschool Kindergarten curriculum designed to alleviate aggressive behaviors in the preschool children. Both interventional and control groups were matchable according to personal data before implementation of the program. A statistically significant difference was found between interventional and control groups with lower mean victim score in the posttest compared to pretest $(p=.005)$. While, no statistically significant difference was found between pre and post test in interventional and control groups ( $p=.16$ and 1.000, respectively). Second step violence prevention program, decreased victimization among interventional group. Perpetration had slightly decreased after implementation of the program with no statistically significant difference. Implementing enrichment programs for preschool children to prepare them socially for school world, thus increasing their chances of social success and decreasing aggression.
\end{abstract}

Key Words: Violence prevention program, Aggressive behaviors, Preschool children

\section{INTRODUCTION}

Aggressive and disruptive behavior is one of the most enduring dysfunctions in children. It frequently results in high personal and emotional costs not only to children but to their families and to society in general, if left untreated. ${ }^{[1]}$

Aggression is a multifaceted learned behavior that involves the perpetrator's act of forcefully injuring or harming someone with malicious intent against the victim's own will. ${ }^{[2]}$ Children's aggression has multi-factorial causes; biological, psychosocial, developmental and/or environmental patterns occurring in early childhood. ${ }^{[3]}$
Every day worldwide, an estimated 227 children and youths (age 0-19 years) die as a result of interpersonal violence (The global burden of disease: 2004). ${ }^{[4]}$ It is worthy noted that for each death many more are hospitalized with injuries from this violence ${ }^{[5]}$ Factors such as poor social competence, low academic achievement, impulsiveness, truancy and poverty increase individuals' risk of violence. ${ }^{[5,6]}$

The knowledge of Ikeda et al. (2001) ${ }^{[7]}$ suggests that development of violent and aggressive behavior evolves over a long period of time and becomes more resistant to change at adolescence. So, it is important to intervene early. They also added that the onset of minor aggressive acts often begin

*Correspondence: Eman S. Ahmmed; Email: emansayed666@yahoo.com; Address: Faculty of Nursing, Assiut University, Assiut, Egypt. 
as early as age three and physical fighting begins as early as age five. Aggressive behavior that begins early in childhood resulted in more serious delinquency and more violent behavior in the later years.

Experts believe that children at risk for becoming violent youths have been exposed to violence during childhood. ${ }^{[8,9]}$ This exposure can occur in the home, school, in the community, and through media presentations such as the news, video games and movies. Numerous research studies have demonstrated a positive correlation between exposure to violence and later acts of aggressive behavior. ${ }^{[3,10]}$

Parents, teachers, and students are increasingly concerned with violence and aggression in the school setting. Aggression and violence had negative health effects on an individual's sense of well-being. ${ }^{[11,12]}$

Implications for nursing practice include the need for nurses to encourage administrators, teachers, and school nurses to include instruction on aggression and violence prevention to promote awareness of such behaviors in young children and offer strategies that are non-aggressive or violent. ${ }^{[13]}$

Intervening in the preschool years is a developmentally optimal time which is characterized by language development, egocentric thinking (viewing world from their own perspective), memory/attention span improvement, and beginning of intuitive thought, among other things. Socially, this age group displays facial expressions that reflect emotions, begins to feel empathy, forms attachment to others, has a sense of gender and racial identity, sees peers as individuals and forms friendships based on trust and shared interests. So, the researchers chose preschool stage.

A review of the literature revealed that there are numerous, marketed, violence prevention programs that claim to have a positive effect on reducing aggressive behavior in children, and one of them is the second step which the researchers used in this study. ${ }^{[14]}$

This study was directed toward assessing a violence prevention program as a modality for developing more pro-social alternative behaviors toward conflict resolution other than aggression and violent behavioral responses.

\subsection{Significance of the study}

The nursing students should have the opportunity to observe and deal with healthy preschoolers before dealing with diseased hospitalized children. During this time, the researchers observed aggressive behaviors among preschool children during supervising nursing students in practical part of Pediatric Nursing. Currently, the Egyptian government launched the "NO violence initiative" to minimize aggressive and violent

Published by Sciedu Press behaviors which was concurrent with the researchers' idea of implementing that research.

\subsection{Research hypothesis}

Preschool children who have completed the violence prevention program will have less aggressive behaviors than children who have not completed the violence prevention program.

\subsection{Aim of the study}

The aim of this work was to assess the effect of violence prevention program on aggressive behaviors among preschool children.

\section{SUBJECTS AND METHOD}

\subsection{Research design}

A quasi experimental design was used in this study.

\subsection{Setting}

This study was conducted in Bader Kindergarten at Assiut city that was chosen randomly.

\subsection{Sample}

Two classrooms from KG2 one for the intervention group and the other was control which was chosen by a simple random sample. A power analysis that was conducted to estimate the sample size with Precision Levels $10 \%$ Where Confidence Level is $95 \%$ and $p<.05$ a sample size of 83 was obtained. A sample of 95 children was enrolled. Four of them were excluded because they missed three sessions because of repeated absence. And 91 children continued the research. The inclusion criteria were children aged five to six years old who are able to follow simple directions and have a consistent teacher for the duration of the study.

\subsection{Methods of data collection}

One tool was used for this study which included two parts:

Part I: A structured questionnaire was used to collect sociodemographic data of children, it included sex, number of siblings, birth order, presence of behavioral problems and types, if any and academic performances.

Part II: The Revised Aggression Scale (RAS-K-2) to assess aggression in children. The original Aggression Scale was developed by Orpinas and Frankowski (2001) ${ }^{[15]}$ and revised by Jack, 2009. ${ }^{[16]}$ The instrument has subscales to measure both victimization and perpetration of aggressive acts. This RAS-K-2 has a documented content validity index of 0.80 and demonstrates high internal consistency reliability with a satisfactory Cronbach's alpha of 0.84 . The Cronbach alpha reliability coefficients were 0.68 for the victim subscale and .85 for the perpetrator subscale. 
Scoring: The instrument contains 10 vignettes in two subscales victimization (1-5) and perpetration (6-10), each vignette has a score range from 0-2 with A total score of 20, the higher score representing more aggression.

The Second Step Violence Prevention Program ${ }^{\mathrm{TM}}$ third edition (committee for children (2002) ${ }^{[17]}$ for Preschool Kindergarten curriculum, designed to mitigate aggressive behaviors in the preschool children. It is marketed by the Committee for Children and is comprised of three units that address empathy training, impulse control, and anger management. Each unit has a series of lessons that was presented during a 30 minute time interval twice per week. The entire curriculum contains 28 lessons and was administered over a four month period. The researcher modified the content by removing the last part about transitioning to kindergarten (25 lessons) instead of 28 lessons and the period was 3 months. The curriculum kit contains the necessary interactive tools to implement each of the lessons. These teaching tools include: 25 lesson cards, a teacher's guide, two puppets, a poster, a water-soluble pen, and a songs tape.

The researchers obtained an official permission to collect data from the prime minister of Social Solidarity. A pilot study was carried out on (10\%) of the sample to assess clarity of the sheet and time needed to fulfill the sheet. There was no modifications in the sheet. The researchers spent a lot of time training themselves to use the second step violence prevention program and translate it into Arabic. The content validity for the Arabic form was calculated using five experts in the field of Psychology and Pediatric nursing. Content Validity Index (CVI) for it was 0.87 . The program was left to the highly qualified teachers in the kindergarten to revise it as they had experience in this field. They integrated their curriculum with that of the program.

The design for this study was subject to the internal threats of selection, maturation, history, and testing. ${ }^{[18]}$ In this research design, one threat to the internal validity of the study was selection. The interventional and control groups were matchable in pretest score (before implementation of the program) to control for the effect of selection. Maturation represents another threat to internal validity in our study, it was expected that each child would continue to develop and mature along with his or her peers. History was another identified threat to the internal validity of this study represented by the No Violence Initiative of the government. This initiative had a positive effect in that director and teachers of kindergarten were welcoming and cooperative. To control the threat of testing, avoiding words such as "good" and "that's right" after a child's response helped to avoid these threats. Additionally, the children may have forgotten the pre-test questioning in the three months between pre-test and posttest thereby minimizing any threat due to testing effect. The application of the program requires our daily presence which was impossible, so we spent the first semester preparing and training teachers to assist the researchers and follow up children. Implementation of the program took 3-month period from half of February to half of May during the second semester of the academic year 2015-2016.

\subsection{Ethical considerations}

Approval of ethical committee of Faculty of Nursing-Assiut University was taken. The researcher obtained written consent from mothers' of studied children to collect the data after explaining purpose and the nature of the study and assured voluntary participation and confidentiality.

\subsection{Limitations}

No random assignment of children into interventional and control groups because we must work with the whole class as excluding some is not ethically and not possible.

Since there was a limited areas in the kindergarten, interviewing parents was difficult and the policy of the setting prevent their presence unless, there was a complain, so parents were not included in the program.

\section{RESUlts}

Table 1 shows descriptive characteristics of interventional and control groups related to personal data. There were no statistically significant differences between interventional and control groups related to personal data.

Table 2 represents mean score for ten items victim and perpetrator pre and post test of interventional and control groups. The highest mean in both victim and perpetrators were take away toy, pushing and call bad, respectively in pre and post test among both interventional and control groups.

Table 3 illustrates comparison between mean aggressive score of both interventional and control groups at the pre and posttest. A statistically significant difference was found between interventional and control groups with lower mean victim score in the posttest compared to pretest $(p=.005)$. While, no statistically significant difference was found between pre and posttest in interventional and control groups as regard perpetrator ( $p=.16$ and 1.000 , respectively).

Figure 1 shows a statistically significant difference was found between interventional group in pre and posttest total mean aggressive score with lower mean total aggressive score in the posttest compared to pretest $(p=.038)$. While, no statistically significant difference was found between pre and posttest in control group. 
Table 1. Descriptive characteristics of interventional and control groups related to personal data

\begin{tabular}{|c|c|c|c|c|c|c|}
\hline \multirow{2}{*}{ Personal data } & \multicolumn{2}{|c|}{ Interventional } & \multicolumn{2}{|c|}{ Control } & \multirow{2}{*}{$\chi^{2}$} & \multirow{2}{*}{$p$-value } \\
\hline & No & $\%$ & No & $\%$ & & \\
\hline \multicolumn{7}{|l|}{ Gender } \\
\hline Male & 25 & 56.8 & 30 & 63.8 & 0.47 & .49 \\
\hline Female & 19 & 43.2 & 17 & 36.2 & & \\
\hline \multicolumn{7}{|l|}{ Number of Siblings } \\
\hline 0 & 6 & 13.6 & 1 & 2.1 & & \\
\hline 1 & 17 & 38.6 & 13 & 27.7 & 9.1 & .10 \\
\hline 2 & 16 & 36.4 & 19 & 40.4 & & \\
\hline 3 and more & 5 & 11.4 & 14 & 29.8 & & \\
\hline \multicolumn{7}{|c|}{ Academic Performance } \\
\hline Outstanding & 31 & 70.4 & 28 & 59.6 & & \\
\hline Satisfactory & 8 & 18.2 & 10 & 21.3 & 1.4 & .49 \\
\hline Needs Improvement & 5 & 11.4 & 9 & 19.1 & & \\
\hline \multicolumn{7}{|l|}{ Behavioral Problems } \\
\hline Yes & 14 & 30.7 & 13 & 27.7 & 0.74 & .38 \\
\hline No & 30 & 69.3 & 34 & 72.3 & & \\
\hline \multicolumn{7}{|c|}{ Types of Behavioral Problems } \\
\hline Lying & 14 & 77.8 & 11 & 84.6 & & \\
\hline Stealing & 1 & 5.5 & 0 & 0.0 & 2.1 & .55 \\
\hline Aggressive & 3 & 16.7 & 2 & 15.4 & & \\
\hline
\end{tabular}

Table 2. Mean score for ten items victim and perpetrator pre and post test of interventional and control groups

\begin{tabular}{|c|c|c|c|c|}
\hline & \multicolumn{2}{|l|}{ Pre test } & \multicolumn{2}{|l|}{ Post test } \\
\hline & Interventional & Control & Interventional & Control \\
\hline & Mean \pm SD & Mean \pm SD & Mean \pm SD & Mean \pm SD \\
\hline \multicolumn{5}{|l|}{ Victim } \\
\hline 1-Take away toy & $0.95 \pm 0.20$ & $0.96 \pm 0.20$ & $0.91 \pm 0.29$ & $0.96 \pm 0.20$ \\
\hline 2-Pushing & $0.92 \pm 0.59$ & $0.85 \pm 0.58$ & $0.93 \pm 0.63$ & $0.85 \pm 0.59$ \\
\hline 3-Call bad & $0.39 \pm 0.55$ & $0.47 \pm 0.54$ & $0.18 \pm 0.45$ & $0.47 \pm 0.55$ \\
\hline 4-Hit/kick & $0.11 \pm 0.44$ & $0.06 \pm 0.32$ & $0.000 \pm 0.0$ & $0.06 \pm 0.32$ \\
\hline 5-Biting & $0.01 \pm 0.10$ & $0.02 \pm 0.15$ & $0.000 \pm 0.0$ & $0.02 \pm 0.15$ \\
\hline Total subscale & $2.7 \pm 1.4$ & $2.4 \pm 1.2$ & $2.02 \pm 0.97$ & $2.4 \pm 1.2$ \\
\hline \multicolumn{5}{|l|}{ Perpetrator } \\
\hline 1-Take away toy & $0.78 \pm 0.59$ & $0.51 \pm 0.54$ & $0.86 \pm 0.59$ & $0.51 \pm 0.55$ \\
\hline 2-Pushing & $0.98 \pm 0.66$ & $0.74 \pm 0.64$ & $0.91 \pm 0.71$ & $0.74 \pm 0.64$ \\
\hline 3-Call bad & $0.36 \pm 0.53$ & $0.40 \pm 0.49$ & $0.14 \pm 0.35$ & $0.40 \pm 0.50$ \\
\hline 4-Hit/kick & $0.13 \pm 0.42$ & $0.09 \pm 0.35$ & $0.00 \pm 0.0$ & $0.09 \pm 0.35$ \\
\hline 5-Biting & $0.00 \pm 0.0$ & $0.00 \pm 0.0$ & $0.00 \pm 0.0$ & $0.00 \pm 0.0$ \\
\hline Total subscale & $2.4 \pm 1.9$ & $1.7 \pm 1.5$ & $1.9 \pm 1.3$ & $1.7 \pm 1.5$ \\
\hline
\end{tabular}

Table 4 illustrates relation between personal data and mean victim score among interventional and control groups at the pre and post tests. The only significant item between personal data and mean victim score was gender among interventional and control groups at the pre and post test with lower mean victim score among female sex in the interventional group posttest compared to control group.

No statistically significant differences were found between personal data and both mean perpetrator and total aggressive score among interventional and control groups at the pre and post tests. 
Table 3. Comparison between mean aggressive score of both interventional and control groups at the pre and post test

\begin{tabular}{lllll}
\hline & Pre & Post & T & p value \\
\hline Victim & & & & $.005^{*}$ \\
Interventional & $2.7 \pm 1.4$ & $2.02 \pm 0.97$ & 2.8 & 1.000 \\
Control & $2.4 \pm 1.2$ & $2.4 \pm 1.2$ & 0.000 & \\
$T$ & 1.4 & -1.5 & & 0.16 \\
$p$ value & 0.153 & 0.14 & & 1.000 \\
Perpetrator & & & 1.4 & \\
Interventional & $2.4 \pm 1.9$ & $1.9 \pm 1.3$ & 0.000 & \\
Control & $1.7 \pm 1.5$ & $1.7 \pm 1.5$ & & \\
$T$ & 1.8 & 0.55 & & \\
$p$ value & 0.07 & 0.57 & & \\
\hline
\end{tabular}

$* p<.05$

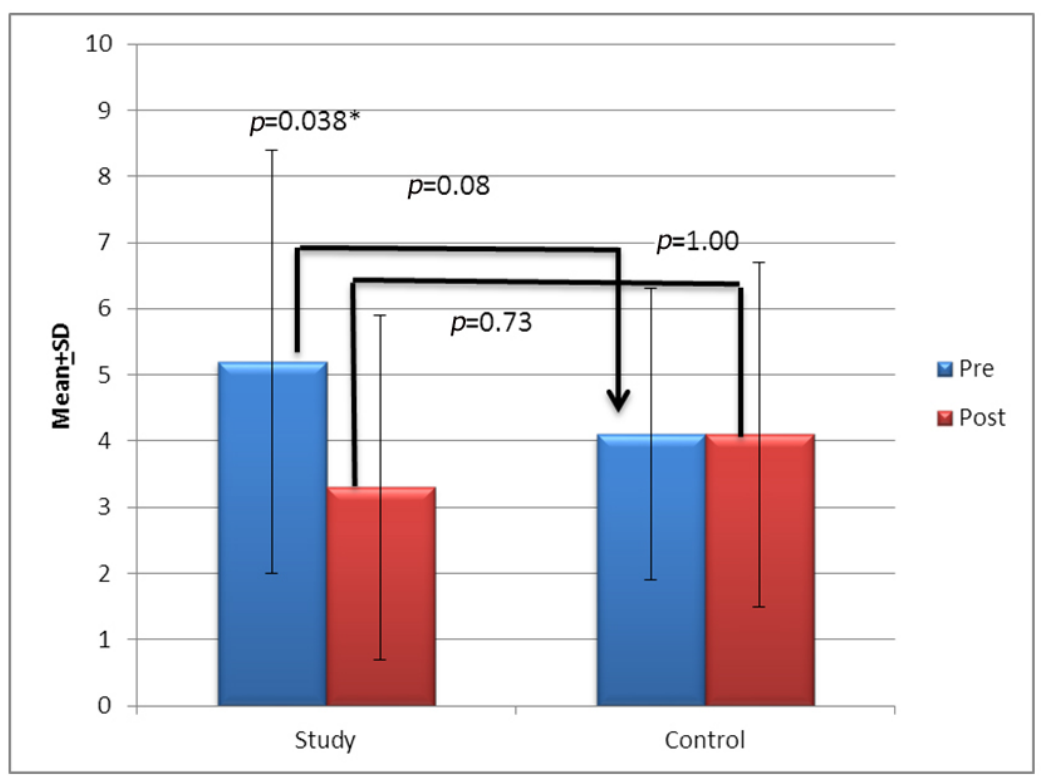

Figure 1. Comparison between total mean aggressive score of both interventional and control groups at the pre and posttests

Table 4. Relation between personal data and mean victim score among interventional and control groups at the pre and post tests

\begin{tabular}{|c|c|c|c|c|c|c|}
\hline \multirow{3}{*}{ Personal data } & \multirow{2}{*}{\multicolumn{2}{|c|}{$\begin{array}{l}\text { Interventional } \\
\text { Victim }\end{array}$}} & \multirow{2}{*}{\multicolumn{2}{|c|}{$\begin{array}{l}\text { Control } \\
\text { Victim }\end{array}$}} & \multirow{3}{*}{$T$ test } & \multirow{3}{*}{$p$ value } \\
\hline & & & & & & \\
\hline & Pre & Post & Pre & Post & & \\
\hline \multicolumn{7}{|l|}{ Gender } \\
\hline Male & $2.8 \pm 1.2$ & $2.3 \pm 0.9$ & $2.1 \pm 0.9$ & $2.1 \pm 0.9$ & 1.69 & .09 \\
\hline Female & $2.7 \pm 1.5$ & $1.7 \pm 1.0$ & $2.9 \pm 1.4$ & $2.9 \pm 1.4$ & 2.38 & $.023 *$ \\
\hline
\end{tabular}

$* p<.05$

\section{Discussion}

Violence touches the life of every child in the country, some more directly than others. A continuum of exposure to violence exists that extends from exposure through the media to being a direct witness, being a victim, and, for too many children, becoming a perpetrator.
There are long term effects of aggression, and this aggression begins early in the child's life. Shaw et al. $(2003)^{[19]}$ reiterate during their research on the developmental trajectories of children stated that $50 \%$ of disruptive children continue to show difficulties throughout the school-age period and into early adolescence, and by then they become resistant to 
change through any intervention program.

Children and youth's exposure to experience and perpetration of interpersonal violence is perhaps one of the most salient and heartbreaking examples of what happen when we fall short in fostering healthy development. In addition to reducing risk for victimization, public health approaches also focus on reducing risk for perpetration of violence by enhancing social and problem solving skills and providing safe environments, supportive relationships, and opportunities for success. ${ }^{[20]}$

Our research hypothesis was that children engaged in violence prevention program will show less aggressive act than children who will not. The most important finding was that our investigation ended with a pessimistic note that a significant difference between interventional and control groups in the post test was founded as victim while, no significant difference as perpetrator as shown in Table 3. The lack of significant impact on perpetration is not entirely surprising given the results of the Stephenson $(2009)^{[21]}$ who stated that second step violence prevention program had no significant impact on aggression and antisocial behaviors for preschool children. Moreover, Alsaker and Valkanover (2012) ${ }^{[22]}$ stated that physical and indirect victimization scores had dropped significantly in the intervention group compared to the control group. It is the case not only in the preschool children but also in middle school children as reported by Espelage et al. (2015) ${ }^{[23]}$ who implemented the second step program and stated no significant improvement in bullying and aggression.

This may be because freedom that children feel after implementing the program was misperceived by the children, this lead to treating their colleagues more freely so, teachers found aggression from children more than previously noted. Our cultivated principles of forgiveness, expressing anger politely faced with parents' principles of rearing their children on not permitting any child to assault him verbally or physically.

However, Grossman et al. (1997) $)^{[24]}$ found that physical aggression and overall negative behaviors decreased from pretest to posttest for the intervention group but increased for the comparison group. Moreover, they also added that at six months post intervention, physical aggression observed in the classroom was significantly lower in the intervention group than in the comparison group.

In addition to Goodwin et al. (2003) ${ }^{[25]}$ who implemented an on site early identification and intervention program for preschool children and reported that this program is an effective strategy to decrease violent and aggressive behavior in preschool children. Pickins (2009) ${ }^{[26]}$ evaluated an early childhood socioemotional program to promote preschooler's social skills and to reduce behavior problems who found a decline in problem behaviors for children at preschool classrooms that implemented the Peace Education foundation program, compared with no treatment controls.

Even though the results were not statistically significant and did not bear the expected outcomes (e.g. lower posttest aggression scores for the interventional group), a great deal of information was gleaned from conducting this study. Yet there were challenges, and these included that children become more free, secure, and the barrier of fear gradually decreased.

In our opinion, most public kindergarten buildings in Egypt didn't have the ideal characteristics as small area of classrooms, playground, computer rooms and other facilities which help children enjoy through learning.

Although, we choose this kindergarten from others which are not public and although they have strict roles in choosing the children who engage in the kindergarten, teachers are not qualified to deal with children in this age group, so these teachers are very restricted with children. They didn't permit them to express their feeling and needs to the extent that they are not permitted to move unless to the bathroom.

The most frequent reported acts of vignette of both victim and perpetrator are take away toy and pushing followed by call bad as shown in Table 2. This can be explained by the fact that we tend to rear our children as being selfishness and that forgiveness means weakness.

Unfortunately, many of us, as parents are perpetrator and our children are victim of our violence. We, as parents rear our children to hit back and revenge those who assaulted him/her to the extent that some parents leave their children's nails uncut to scratch those who assault them.

Some problems evoked between parents of children and teachers as they are not satisfied with our violence prevention program because parents focused only on the learning academic skills rather than modifying behaviors, moreover our violence prevention program decrease the quantity of homework given to children which make them free at home, make more noise while, their parents came back home stressed and tired and need to have rest. Parents used to compare their children's achievement to those of others' in other kindergartens.

The only significant relation between aggression score and personal data is between aggression score and sex of children with lower victimization among female sex in the posttest in the study group as shown in Table 4. This is in accordance 
with Rosenkoetter et al. (2004) ${ }^{[27]}$ who found that classroom based violence prevention program were only successful with girls. However, Stephenson (2009) ${ }^{[21]}$ found no statistically significant gender difference for overt or physical aggression scores. He also added that boys and girls in each group had similar mean aggression scores. This may be because of feminine nature of girls which are more quite and less trouble making than boys.

\section{Conclusion}

Second step violence prevention program, in this study, decreased victimization among interventional group children. While, perpetration had slightly decreased after implementation of the program with no statistically significant difference. There was no significant relation between aggression score and personal data.

\section{RECOMMENDATIONS}

Some parents are victims of violence themselves. Many are so stressed by community conditions that they are unable to serve as the buffer of emotional protection that children need. So, parents need to learn dealing with stress and enhance their ability to help children cope with violence.

Training teachers and parents on impulse control, and anger management as we must be good model for our children since improvement in parents' behavior lead to improvement in their children's behavior.

Implementing enrichment programs for preschool children to prepare them socially for school world, thus increasing their chances of social success and decreasing aggression.

Policy makers should have the decision to employ Pediatric nurse in kindergarten as a school nurse, who should benefit from her unique position in observing and dealing with children to implement violence prevention program and identify and treat any problem.

\section{CONFlicts OF InTEREST Disclosure}

The authors declare that there is no conflict of interest.

\section{REFERENCES}

[1] Lochman JE, Boxmeyer C, Powell N, et al. Effective day care- kindergarten intervention to prevent chronic aggression (Internet). Encyclopedia on early childhood development. Published online January 2012.

[2] Jack DE. Concept Development of Violence e Behaviors, in Children. Presented at a NURS 812 lecture at Widener University, Chester, PA. 2002, March 4.

[3] Pratt H, Greydanus D. Violence: Concepts of its impact on children and youth. Pediatric Clinics of North America. 1999; 50: 963-1003.

[4] The global burden of disease: 2004 update. Geneva, World Health Organization. 2008. Available from: http://www.who.int/healthinfo/global_burden_dis ease/estimates_regional/en/index.html

[5] Krug EG et al. eds. World report on violence and health. Geneva, World Health Organization. 2002.

[6] Farrington DP. Childhood risk factors and risk focussed prevention. In Maguire M, Morgan R, Reiner R, eds. The Oxford Handbook of Criminology, 4th ed. Oxford, Oxford University Press; 2007. 602-640p.

[7] Ikeda J, Simon T, Swahn M. The prevention of youth violence: The rationale for and characteristics of four evaluation projects. American Journal of Preventative Medicine. 2001; 20(15): 15-21. https ://doi.org/10.1016/S0749-3797(00)00269-5

[8] Augustyn M, Frank D, Posner M, et al. Children who witness violence, and parent report of children's behavior. Archives of Adolescent Medicine. 2002; 156: 800-803. https://doi .org/10.1001/ archpedi.156.8.800

[9] Daane D. Child and adolescent violence. Orthopaedic Nursing. 2003; 22(1): 23-31. https://doi.org/10.1097/00006416-2003010 00-00008

[10] Vastag B. Does video game violence sow aggression? JAMA. 2004; 291: $1822-1824$
[11] Snyder S. City public schools shows drop in crime. The Philadelphia Inquirer. 2006.

[12] Fisher K, Kettl P. Teacher's perceptions of school violence. Journal of Pediatric Health Care. 2003; 17(2): 79-83. https ://doi.org/ 10.1016/S0891-5245(02) 88320-1

[13] Palinkas L, Prussing E, Landsverk J, et al. Youth violence prevention in the aftermath of the San Diego eat county school shootings: A qualitative assessment of community explanatory models. Ambulatory Pedistrics. 2003; 3: 246-252. https://doi.org/10.1367/15394409(2003)003<0246:YPITAO>2.0.CO;2

[14] Nansel T, Overpeck M, Haynie D, Ruan J, Scheidt P. Relationships between bullying and violence among US youth. Archives of Pediatric Adolescent Medicine. 2003; 157: 348-353. PMid:12695230 https://doi.org/10.1001/archpedi.157.4.348

[15] Orpinas P, Frankowski R. The aggression scale: A self-report measure of aggressive behavior for young adolescents, Journal of Early Adolescence. 2001; 21(1): 50-67. https://doi.org/10.1177/ 0272431601021001003

[16] Jack D. Investigation of the Effects of a Violence Prevention Program in Reducing Kindergarten-aged Children's Self-reported Aggressive. (dissertation). (Widener) : University of Widener, Faculty of the School of Nursing; 2009.

[17] Committee for Children. Second Step: A Violence Prevention Curriculum,Preschool/Kindergarten (3rd ed.). 2002. Seattle, WA: Author

[18] Campbell D, Stanley J. Experimental and Quasi-Experimental Designs for Research. 1963.

[19] Shaw D, Gilliom M, Ingoldsby E, et al. Trajectories leading to schoolage conduct problems. Developmental Psychology. 2003; 39: 189200. https://doi.org/10.1037/0012-1649.39.2.189

[20] Tharp AT, Simon TR, Saul J. Preventing violence against children and youth. Journal of Safety Research. 2012; 43: 291298. PMid:23127679 https ://doi.org/10.1016/j.jsr. 2012 .08 .014 
[21] Stephenson CW. The effectiveness of a violence prevention program used as a nursing intervention on aggression among children in prekindergarten. (dissertation).( prekindergarten), prekinder gartenuniversity. 2009.

[22] AlSaker F, Valkanover S. The Bernese program against victimization in kindergarten and elementary school. Newdirections for Youth Development. 2012; 133: 15-28.

[23] Espelage D, Low S, Polanin J, et al. Clinical trial of second step middle school program: impact on aggression \& victimization. Journal of Applied Developmental Psychology. 2015; 37: 52-63. https://doi.org/10.1016/j.appdev. 2014.11.007

[24] Grossman D, Neckerman H, Koepsell T, et al. Effectiveness of a violence prevention curriculum among children in elementary school:
A randomized controlled trial. The Journal of American Medical Association. 1997; 277: 1605-1611. https://doi.org/10.1001/ jama.1997.03540440039030

[25] Goodwin T, Pacey K, Grace M. Childreach: Violence prevention in preschool settings. Journal of Child and Adolescent Psychiatric Nursing. 2003; 16: 52-61. https://doi.org/10.1111/j.1744 $-6171.2003 . t b 00348 \cdot x$

[26] Pickins J. Socio-emotional training program promotes positive behavior in preschoolers. Peace Education foundation. 2009.

[27] Rosenkoetter LI, Rosenkoetter SE, Ozretich RA, et al. Mitigating the harmful effects of violent television. Journal of Applied Developmental Psychology. 2004; 25: 25-47. https://doi.org/10.1016/j. appdev.2003.11.005 